\title{
DISPONIBILIDADE DO DESGASEIFICADOR A VÁCUO RH*
}

\author{
André Luiz Monteiro Martins ${ }^{1}$ \\ Fábio Oliveira da Silva \\ Fernando Neves Francisquine ${ }^{3}$ \\ Hugo Cabral Folly ${ }^{4}$ \\ Matheus Sexto Alexandre Pereira \\ Rodrigo da Silva Magalhães \\ Thiago Aranha da Silva
}

\section{Resumo}

O objetivo do projeto foi otimizar a disponibilidade e o tempo de utilização do equipamento responsável pelo refino secundário de aço líquido da CSN, o Desgaseificador a vácuo $\mathrm{RH}$. Esta otimização ocorreu através da monitoração de eventos gerados por sensores instalados no equipamento para verificar quando o mesmo iniciou a operação e qual foi o tempo necessário para completar o processo. O Disponibilidade do Desgaseificador a Vácuo $\mathrm{RH}$ se trata de uma ferramenta gerencial que realiza o mapeamento completo da produção no Desgaseificador durante vinte e quatro horas por dia, capaz de mapear o tempo do processo com base no tempo padrão do grau de aço e tempo de parada do equipamento, apontando todos os problemas que afetam a produção.

Palavras-chave: Desgaseificador; Vácuo; Refino secundário.

\section{Abstract}

\section{AVAILABILITY OF RH VACCUM DEGASSER}

The project goal was to optimize the availability and the uptime of the equipment responsible for the secondary refining of liquid steel on CSN, the $\mathrm{RH}$ Vacuum Degasser. This optimization has occurred over the monitoring of events generated by sensors installed in the device to determine when it has started operation and which was the time required to complete the process. The Availability of $\mathrm{RH}$ Vacuum Degasser is a management tool that performs the full mapping production in the Degasser for twenty four hours a day, capable of mapping processing time based on the standard grade steel time and downtime of the equipment, pointing out all the problems affecting production.

Keywords: Degasser; Vaccum; Secondary refining.

1 Bacharel em Tecnologia da Informação, Analista de Tecnologia de Automação, Gerência Geral de Engenharia, Companhia Siderúrgica Nacional, Volta Redonda, Rio de Janeiro, Brasil.

2 Bacharel em Tecnologia da Informação, Especialista de Tecnologia de Automação, Gerência Geral de Engenharia, Companhia Siderúrgica Nacional, Volta Redonda, Rio de Janeiro, Brasil.

3 Bacharel em Tecnologia da Informação, Analista de Tecnologia de Automação, Gerência Geral de Engenharia, Companhia Siderúrgica Nacional, Volta Redonda, Rio de Janeiro, Brasil.

4 Engenheiro de Tecnologia da Informação, Analista de Tecnologia de Automação, Gerência Geral de Engenharia, Companhia Siderúrgica Nacional, Volta Redonda, Rio de Janeiro, Brasil

5 Bacharel em Tecnologia da Informação, Analista de Tecnologia de Automação, Gerência Geral de Engenharia, Companhia Siderúrgica Nacional, Volta Redonda, Rio de Janeiro, Brasil.

6 Engenheiro Metalúrgico, Engenheiro de Desenvolvimento, Gerência Geral de Processo da Metalurgia, Companhia Siderúrgica Nacional, Volta Redonda, Rio de Janeiro, Brasil.

7 Bacharel em Tecnologia da Informação, Analista de Tecnologia de Automação, Gerência Geral de Engenharia, Companhia Siderúrgica Nacional, Volta Redonda, Rio de Janeiro, Brasil. 


\section{INTRODUÇÃO}

O refino secundário do aço líquido é um passo significativo para siderurgia atual, é através deste processo que a indústria consegue fornecer material para a produção de automóveis, eletrodomésticos, enlatados e etc. $O$ referido processo ocorre na Aciaria, área siderúrgica responsável por transformar o ferro gusa em aço mediante queima de impurezas e adição de materiais.

A produção do ferro gusa é feita no alto forno a partir do minério de ferro, do sínter, do coque, da pelota e do carvão pulverizado. Estas matérias primas são carregadas no forno, e através de um sopro de oxigênio aquecido a uma temperatura de aproximadamente $1000^{\circ} \mathrm{C}$ o minério de ferro se liquefaz, separando-se do oxigênio ao qual geralmente está associado quando encontrado na natureza. A este processo dá-se o nome de redução.

Neste estágio, o ferro em sua forma líquida conhecido como ferro gusa ainda não possuí as características necessárias para se obter os produtos desejados e por isso precisa ser refinado. Na etapa de refinamento primário, o gusa é carregado em uma panela de aço até o convertedor, onde mistura-se sucata, e através de um sopro de oxigênio em alta pressão reage com o carbono presente em sua composição e é transformado em aço.

Alguns clientes necessitam de um tipo especial de aço e para atendê-los é necessário executar mais um tipo de refinamento, o conhecido refino secundário.

\subsection{Refino Secundário}

A CSN possui atualmente quatro equipamentos responsáveis pelo refino secundário de aço líquido:

- Duas estações de borbulhamento;

- Um forno panela;

- Um desgaseificador a vácuo RH (Ruhstall Heraeus).

As estações de borbulhamento têm a finalidade de permitir ajustes finos de composição química dos aços, através de máquinas de injeção de arames. 0 equipamento Não é capaz de aquecer o aço, somente faz-se resfriamento com adição de material endotérmico.

No forno panela o tratamento é efetuado através do aquecimento do aço, utilizando energia elétrica. As adições de elementos de ligas e desoxidantes são feitas paralelamente a agitação do banho por sopro de gás inerte e/ou agitação eletromagnética. Este equipamento é muito utilizado para aços que possuem grandes adições de ligas devido à capacidade de aquecimento no próprio equipamento.

O Desgaseificador a vácuo $\mathrm{RH}$ trabalha com um vaso que veda a panela com aço líquido assim que ela chega no equipamento. $O$ tratamento é totalmente efetuado sob vácuo e permite a obtenção de teores ultra baixos de carbono necessários para produção dos aços voltados para indústria automobilística por exemplo, pois altera a curva de equilíbrio entre o carbono e o oxigênio quando comparado ao tratamento sob pressão atmosférica. 


\subsection{Motivação}

A visão da gestão com relação ao tempo de produção e das paradas do equipamento eram muito superficiais antes do projeto. Os problemas menores que aconteciam não eram relatados aos superiores por serem considerados irrelevantes, apenas os de grande proporção eram expostos através de formulários preenchidos a mão e mesmo assim sem o detalhamento adequado. Por este motivo a direção da empresa solicitou o desenvolvimento de uma ferramenta capaz de mapear os passos da produção no Desgaseificador, informando qual o tempo efetivo de utilização e os motivos que causaram parada ou atraso no processo.

\section{MATERIAIS E MÉTODOS}

O foco inicial do projeto foi voltado ao Desgaseificador a Vácuo pois se trata de um equipamento responsável por grande parte da demanda mas não será exclusivo, os planos futuros da empresa englobam a implantação de projetos similares também nos outros equipamentos de refino secundário da Aciaria.

O projeto Disponibilidade do Desgaseificador a Vácuo $\mathrm{RH}$ consiste em um sistema automatizado capaz de relatar detalhadamente todas as operações que foram realizadas no equipamento ao longo do dia, exibindo os dados em forma de gráficos e relatórios padronizados.

Quando o tratamento de refino do aço é iniciado no equipamento, o sistema capta o sinal do C.L.P. (Controlador Lógico Programável) ao qual está interligado, e o registra baseado na programação atual de produção da CSN. O mesmo acontece ao fim do tratamento, gerando assim um evento de tratamento no sistema.

A panela com o gusa necessita de um determinado tempo para se movimentar e ser posicionada adequadamente no equipamento, este passo também é levado em consideração e registrado baseado em estimativas. Esta etapa dura aproximadamente dez minutos e acontece quando a panela chega e quando é retirada da posição de tratamento.

Todo e qualquer procedimento que não se enquadre nos dois eventos relatados anteriormente é considerado como um período de ociosidade do Desgaseificador, sendo assim ele precisa ser justificado pela equipe de operação. No momento que é iniciado um processo de tratamento padrão, o sistema verifica se houve um período ocioso, e em caso positivo exibe um alerta para o operador informar o motivo do equipamento não estar efetivamente executando a função para a qual foi criado.

\section{RESULTADOS E DISCUSSÃO}

Totalmente desenvolvido com recursos internos, o projeto não teve nenhum custo com contratação de terceiros, a própria equipe de automação da empresa com auxílio da equipe de processo e operações foi capaz de desenvolver e implantar a ferramenta.

Um mês após a implantação já foi possível analisar os dados e verificar a eficiência da aplicação. Os relatórios mostravam exatamente o tempo de utilização do equipamento e quais eram os principais problemas que estavam impactando na produção, sendo assim a gestão pôde atuar priorizando os principais problemas que tomavam mais tempo para ser corrigido. 


\subsection{Análise de Dados}

O sistema disponibiliza relatórios por período e relatórios diários. Analisando um dia específico (tabela Relatório diário) podemos verificar que o Desgaseificador ficou operando durante 14.56 horas efetivas do dia e somando-se as 4.95 horas que são necessárias para a operação, já que se trata da movimentação e posicionamento adequado da panela com o gusa no equipamento, temos um total de 19.51 horas do dia que foram utilizadas para o refino de aço, nas 4.49 horas restantes o processo não foi executado devido a manutenções e outros problemas.

Tabela 1. Relatório diário

\begin{tabular}{ccc}
\hline Motivos & \% & Tempo(h) \\
\hline Tempo Operando & 60.65 & 14.56 \\
\hline Movimentação da Panela e Vaso & 20.61 & 4.95 \\
\hline Falta de gusa & 11.31 & 2.71 \\
\hline Projeção das pernas & 4.3 & 1.03 \\
\hline Manutenção programada & 2.7 & 0.65 \\
\hline Adequação do tempo entre liberação a abertura & 0.41 & 0.1 \\
\hline
\end{tabular}

As informações podem ser visualizadas também em forma de gráficos, como mostra a Figura 1.

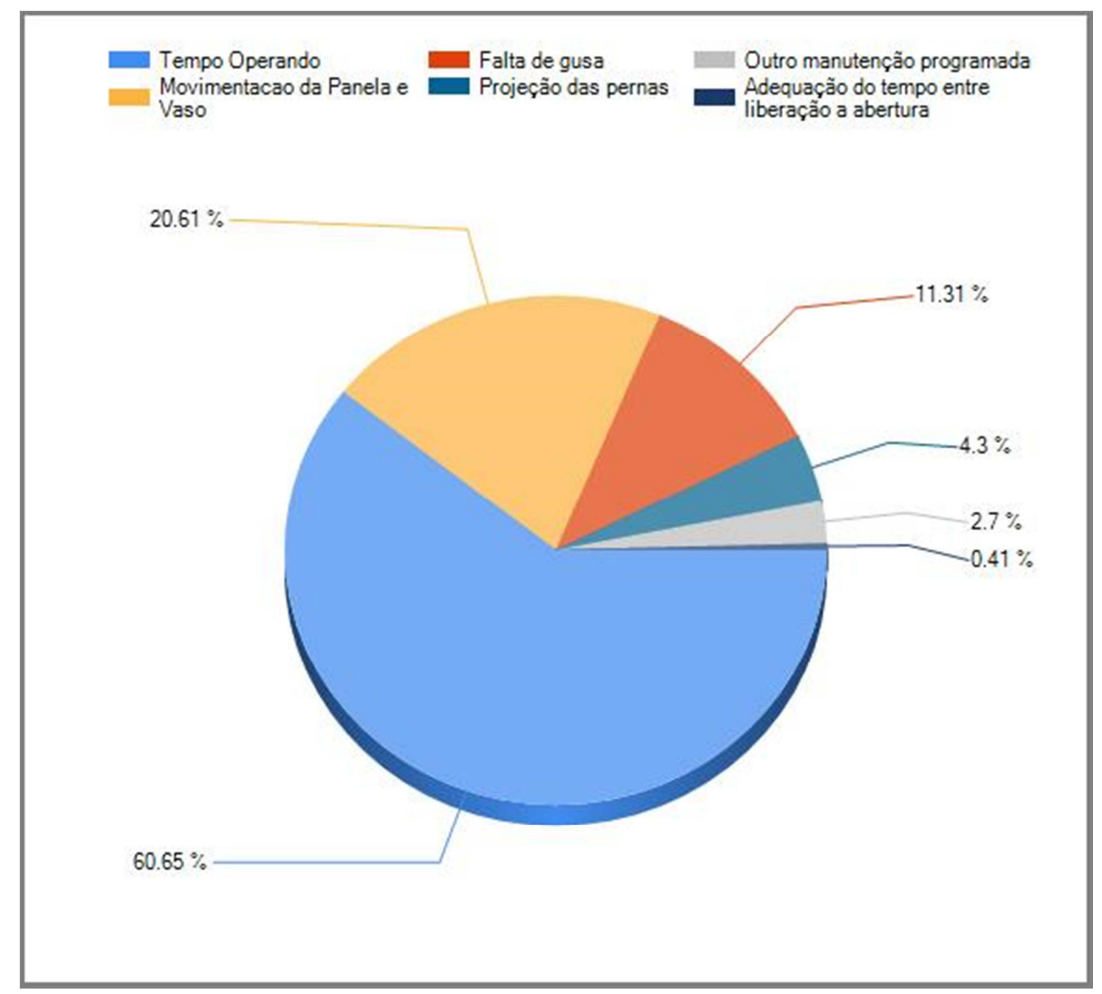

Figura 1. Relatório Diário.

Os dados apresentados podem parecer irrelevantes a princípio, mas em um período maior acabam se tornando bastante significativos. As prospecções feitas pela CSN estimaram um ganho potencial de até cinco milhões ao ano caso o tempo de utilização do Desgaseificador a Vácuo fosse otimizado em 5\%. 


\section{CONCLUSÃO}

O objetivo foi alcançado, agora a empresa possui uma ferramenta capaz de exibir todos os eventos que acontecem no Desgaseificador a Vácuo, a partir deste ponto a gestão pode tomar as melhores decisões para acelerar o processo de produção de aços especiais.

Este projeto foi solicitado pela direção da CSN devido à importância do equipamento. A demanda para este tipo de aço cresceu e com isso a necessidade de produzir mais em menos tempo, hoje a maior parte do material produzido na área metalúrgica da usina é voltada para estes clientes e o Disponibilidade do Desgaseificador a Vácuo está servindo de suporte para agilizar a produção sem a necessidade de fazer altos investimentos, como, por exemplo, a montagem de um novo equipamento de refino secundário. 